Published online 2017 April 13.

Abstract

\title{
Comparison of Bedside Sonography with Ct Scan in Diagnosis of Pneumothorax
}

\author{
Manizhe Ataei ${ }^{1,}$ \\ ${ }^{1}$ Bandarlenge Hospital, Iran \\ "Corresponding author: Manizhe Ataei, Bandarlenge Hospital, Iran. E-mail: manizhe.ataei64@gmail.com \\ Received 2016 December 21; Accepted 2017 February 08.
}

\begin{abstract}
Background: Ultrasound is the choice modality in the unstable patients and after performing certain procedures, such as a thoracentesis or the placement of a central venous line, which helps to rule out an iatrogenic pneumothorax. Upright AP radiograph has less sensitivity in diagnosing pneumothorax in comparison with ultrasound. Ct scan is more sensitive in diagnosis occult pneumothoraces but Bedside ultrasound is prefferedt in unstable situations without any radiation exposure.so we aimed to compare sensitivity of sonography with ct scan in patients who are suspicious to pneumothorax after thoracentesis or the placement of a central venous line or intubatin.

Methods: A radiologist performed bedside sonography first and then chest chestct scan was performed for 40 patients and was interpreted without knowing ultrasound results Absence of lung sliding, loss of 'comet-tail artifacts and Lung-point sign were assumed as sonographic criteria for diagnosis pneumothorax

Results: The result of CT and sonography was the same in 38 case (18 case pneumothorax and 20 case without pneumothorax) 2 cases with small occult pneumothorax were not diagnosed with sonography but pneumothorax was reported at CT scan.

Conclusions: Sonography is valuable method in diagnosis pneumothorax in unstable patients after invasive thoracic procedures.
\end{abstract}

This is an abstract presented in the 33rd Iranian congress of radiology (ICR) and the 15th congress of Iranian radiographic science association (IRSA)

Copyright (c) 2017, Tehran University of Medical Sciences and Iranian Society of Radiology. This is an open-access article distributed under the terms of the Creative Commons Attribution-NonCommercial 4.0 International License (http://creativecommons.org/licenses/by-nc/4.0/) which permits copy and redistribute the material just in noncommercial usages, provided the original work is properly cited. 